\title{
A LITERATURA NEGRA INFANTIL COMO PRÁTICA ANTIRRACISTA NAS AULAS DE GEOGRAFIA
}

\author{
Ana Flávia Borges de Oliveira \\ LAGEPOP-IG-Universidade Federal de Uberlândia - UFU. \\ E-mail: anaflaviaborges97@ hotmail.com \\ Adriany de Ávila Melo Sampaio \\ LAGEPOP-IG- Universidade Federal de Uberlândia - UFU. \\ E-mail: adrianyavila@gmail.com
}

\begin{abstract}
RESUMO
Este artigo tem como intenção aproximar o Ensino de Geografia com a Literatura Negra Infantil como forma de aplicabilidade da Lei 10639/2003 na sala de aula. A Lei 10639/2003 estabelece a obrigatoriedade da História e Cultura da África e Afro-brasileira nos sistemas de ensino, reconhecendo a importância do combate ao racismo, com lutas e ações afirmativas e positivas para a construção de uma educação antirracista no ambiente escolar. Como prática de ensino no combate à discriminação racial, a Literatura Negra juntamente com a Geografia trabalha de maneira lúdica os conteúdos geográficos, ressaltando assim, a importância da interdisciplinaridade entre as disciplinas. $\mathrm{O}$ uso de diferentes linguagens nas aulas de Geografia mostra a necessidade de trocas e cooperação entre disciplinas distintas para que obtenham uma compreensão mais ampla da realidade, desconstruindo o modo tradicional de ensinar os aspectos geográficos, sendo capaz de aproximar e atrair o interesse dos alunos pela Geografia, como também desenvolver a leitura e agir de forma crítica para às questões étnico-raciais.
\end{abstract}

Palavras-chave: Antirracismo; Educação Étnico-Racial; Interdisciplinaridade; Lei 10639/2003.

\section{INTRODUÇÃO}

O Ensino de Geografia busca inserir no contexto escolar diferentes linguagens no processo de ensino-aprendizagem, procurando tornar o conhecimento geográfico mais interessante, utilizando um recurso metodológico que cria estratégias de ensino que permitam deixar as aulas mais dinâmicas e ricas, garantindo que inserir a Literatura Negra na Geografia contribui para a ressignificação da matriz africana e o entendimento das reivindicações do negro de forma positiva, oferecendo ao professor a oportunidade da luta contra a discriminação racial.

Nos Livros Didáticos de Geografia nos deparamos com a invisibilidade dos negros ou representados de maneira negativa em cargos e posições subalternas, e a Literatura Negra Brasileira vem de um histórico de representação negativa das pessoas negras. Estre quadro é alterado em meados do século $\mathrm{XX}$, quando autores negros começam a escrever sua própria história e a reproduzir de forma positiva sua vivência, seu ponto de vista e a representação dos negros na Literatura Negra. 
A Literatura Infantil tem um papel importante no trabalho pedagógico do professor em sala de aula. Trabalhar este recurso metodológico contribui para debater o racismo no ambiente escolar e na sociedade no qual contempla em seu enredo a representatividade negra, como também a valoriza as Culturas Africanas e Afrobrasileiras, a fim de possibilitar a vivência de sua própria história. Assim, o ensino da cultura e história afro-brasileira precisa, primeiramente, desmitificar conceitos negativos enraizados na sociedade brasileira que, ao longo da história, foram vinculados ao negro e a sua cultura com a finalidade de inferioriza-lo por meio de palavras e termos pejorativos que o desqualificam como seres humanos (RAMOS; GOMES; SAMPAIO, 2017).

Com o sentido de estudar uma Geografia para as Relações Étnico-Raciais, a Literatura Negra Infantil propõe uma forma de atender a Lei no Ensino de Geografia, e por meio dessa linguagem interdisciplinar que os personagens e autores negros/as retomam sua integridade enquanto seres humanos, rompendo a reprodução de estereótipos presentes na prática literária, e através de propostas pedagógicas consiga promover uma educação igualitária e antirracista.

Desta forma o presente artigo tem como objetivo aproximar a Literatura com a Geografia como forma de inserir a Lei 10639/2003 na sala de aula. Será abordada a luta do Movimento Negro para a implementação da Lei 10639/2003 no sistema educacional, e seus impactos na Educação Básica com a finalidade de romper com a reprodução de paradigmas racistas e valorizar a cultura negra no processo educacional, reconhecendo o negro como elemento importante para a formação da sociedade.

Será analisado o uso da Literatura Negra como atividade pedagógica no Ensino de Geografia, mostrando que "a literatura permite ensinar, de forma lúdica, diferentes conteúdos da Geografia, contribuindo assim para a aplicação da Lei n ${ }^{\circ} 10.639 / 2003$ ” (RAMOS; GOMES; SAMPAIO, 2017), como também as contribuições da interdisciplinaridade entre a Geografia e a Literatura Infantil Negra e propor práticas antirracistas a partir da integração interdisciplinar no ambiente escolar.

\section{A LEI 10639/2003 E SEUS IMPACTOS NA EDUCAÇÃO BÁSICA}

No processo histórico brasileiro, o Movimento Negro, desde o início do século $\mathrm{XX}$, luta para que as questões raciais sejam debatidas e inseridas no sistema educacional 
abordando as relações étnico-raciais, importantes para a formação da cidadania, e que tendem ao fim do racismo (OLIVEIRA, 2019).

No ano de 2003, o Brasil reconheceu a importância das lutas e pressões antirracistas dos Movimentos Sociais Negros e Indígenas, e a necessidade de uma educação antirracista com um ensino democrático que inserisse a história de todos os grupos étnicos que formaram o país, aprovando a Lei $n^{\circ} 10.639 / 2003$, alterando o artigo 26-A que estabelece as Diretrizes e Bases da Educação Nacional, no qual tornou obrigatório o ensino de História e Cultura Africana e Afro-Brasileira. No ano de 2008, foi aprovada a Lei $n^{\circ} 11.645 / 2008$ alterando o artigo 26-A da LDB, inserindo a obrigatoriedade das Questões Indígenas no currículo da rede de ensino (OLIVEIRA, 2019).

No parágrafo primeiro do Artigo 26, "propõe-se uma renovação curricular. Para tanto, os(as) professores(as) devem enfatizar durante as aulas com seus(suas) alunos(as) a cultura africana e afrodescendente, como um patrimônio não material de fundamental importância para a formação da nação brasileira” (MELO; GONÇALO, 2017, p. 101).

A promulgação da Lei 10639/2003 não colocou um ponto final na questão racial, segundo Rodrigues e Aquino (2010, p.3), esta Lei ainda "não conseguiu convencer as mentes mais esclarecidas da sociedade brasileira de que os professores precisam ser preparados para atuarem na educação de base e para isso é necessária a reformulação dos programas de cursos de graduação”.

Daí a necessidade de se insistir e investir para que os professores, além de solida formação na área especifica de atuação, recebem formação que os capacite não só a compreender a importância das questões relacionadas à diversidade étnico- raciais, mas a lidar positivamente com elas e, sobretudo criar estratégicas pedagógicas que possa auxiliar a reeducá-las (Brasil, 2005, p. 17).

A escola, como instituição responsável pela transmissão do conhecimento e pela Educação das Relações Étnico-Raciais, é o ambiente ideal para a superação do racismo e da discriminação étnico-racial, e possui papel importante na propagação e na valorização da cultura e história dos africanos e afro-brasileiros. Segunda Gomes (2003, p. 77), "a escola, como um espaço que promove a igualdade e tendem eliminar toda forma de discriminação e racismo, revela-se como um espaço em que a inferiorização dos negros são difundidas", e é através da Educação, que a sociedade se torna consciente em respeitar a pluralidade dos grupos étnico-raciais e a lutarem por atitudes antirracistas. 
A necessidade da Lei 10639/2003 para colocar em prática o ensino de temas sobre a África e suas culturas que promovam uma educação antirracista, visa além da inclusão de conteúdos no currículo, o fortalecimento de repensar as Relações ÉtnicoRaciais oferecidas para aprendizagem em todo o sistema de ensino escolar.

Essa alteração não se resume apenas a ser mais um mecanismo para combater a intolerância no ambiente escolar, mas visa, também a formar futuros cidadãos com uma consciência de que a sociedade brasileira é multiétnica, culturalmente diversa e que foi formada sob a exploração brutal de africanos escravizados, sendo esses conteúdos importantes tanto para as escolas públicas de bairros periféricos, onde há grande presença de alunos negros, como também em instituições particulares de elite em todo o país, nos seus diversos segmentos. (MOREIRA, 2015, p. 23).

É importante ressaltar que essa lei representa um grande avanço para a Educação e para a sociedade, reconhecendo a pluralidade étnico-racial na história do país, mostrando a contribuição do povo negro na formação da sociedade brasileira e a valorização de características étnicas e culturais dos diferentes grupos sociais que convivem no território nacional.

A efetivação da lei, não é somente tarefa dos professores, mas sim de toda a escola, e de todas as disciplinas. A discussão sobre a história e cultura africana e afrobrasileira após a promulgação da lei, evidencia a falta de conhecimento por parte dos professores e ausência de materiais para serem discutidos em sala de aula. Nos dias atuais, precisam existir incentivos para reafirmar a importância da formação inicial e continuada dos professores e a produção de materiais sem estereótipos com o intuito de ressignificar ideias e visões sobre a cultura africana e afro-brasileira.

\section{A LITERATURA NEGRA INFANTIL COMO PRÁTICA INTERDISCIPLINAR NO ENSINO DE GEOGRAFIA}

O Ensino de Geografia tem papel definitivo na formação da cidadania e a partir da Lei 10639/2003, é fundamental que os profissionais da Educação em geral trabalhem a História e Cultura da África e Afro-brasileira, a partir da Literatura ligada com as temáticas das questões raciais, com intuito de fortalecer a construção das identidades e autoestima das crianças negras, a partir de livros literários que retratam a realidade das pessoas negras.

A Literatura Negra é diferente da Literatura Afro-brasileira, pelo fato, da primeira ser escrita por autores negros e seus escritos podem vir não somente em forma de denúncia do racismo, mas com os desdobramentos na vida do povo negro, como 
reivindicações do período escravocrata brasileiro, narrações de viagens, histórias para crianças enfatizando a beleza do cabelo, cor da pele, experiências pessoais sofridas por discriminação racial que ainda fazem parte do cotidiano brasileiro. Ambas possuem elementos importantes da cultura africana e são necessárias para o processo de construção identitária na infância.

Djamila Ribeiro (2019) afirma sobre a importância de apresentar para as crianças livros com personagens e autores negros que não possuem estereótipos negativos, e confirma:

Um ensino que valoriza as várias existências e que referencie positivamente a população negra é benéfico para toda a sociedade, pois conhecer histórias africanas promove outra construção da subjetividade de pessoas negras, além de romper com a visão hierarquizada que pessoas brancas têm da cultura negra, siando do solipsismo branco, isto é, deixar de apensas ver humanidade entre seus iguais. (RIBEIRO, 2019, p. 16).

Se faz necessário no Ensino de Geografia, o uso de diversas áreas de conhecimento, como a Literatura, para que haja uma interdisciplinaridade com conteúdos pedagógicos das temáticas, assim, aproxima o aluno da realidade do seu cotidiano. O diálogo entre Geografia e a Literatura melhora a interação entre essas duas áreas, possuindo a capacidade de desenvolver no aluno visões críticas do mundo a respeito do cenário atual sobre o racismo.

Nos dizeres de Bonatto et al. (201, p. 172), a interdisciplinaridade "é um importante elo entre o entendimento das disciplinas nas suas mais variadas áreas, porque abrange temáticas e conteúdos, permitindo, dessa forma, recursos inovadores e dinâmicos em que as aprendizagens são ampliadas". É preciso haver diversificações de metodologias para ser compreendido as abordagens geográficas em sala de aula, para que haja a aproximação com a realidade dos alunos.

De acordo com Klug e Tessmann (2014, p. 11), “a interdisciplinaridade não tem o papel de anular as disciplinas, mas de usar o conhecimento de várias disciplinas entre si para haver a compreensão de mundo e valorizar processo de aprendizagem”. A interdisciplinaridade se mostra uma importante ferramenta na construção de uma perspectiva mais ampla do conhecimento, visando diálogo, trocas de saberes e integração entre as diferentes linguagens.

Como prática de ensino no combate à discriminação racial, a Literatura Negra juntamente com a Geografia trabalha de maneira lúdica os conteúdos geográficos, de acordo com Sampaio e Sampaio (2016), conforme citado por Ramos et al. (2017, p. 67), 
quanto as categorias de análises da Geografia que se relacionam com a construção histórica e geográfica dos sujeitos formadores da sociedade brasileira:

A categoria território na Geografia pode ser utilizada para trabalhar as questões sobre a importância do negro na formação cultural brasileira, por meio de um ensino que demonstre como os africanos foram retirados violentamente de seu continente, trazidos ao Brasil e a outras partes do mundo, por meio de um processo migratório escravista, extremamente desumano. (SAMPAIO; SAMPAIO, 2016, apud Ramos et al., 2017).

Com intuito de se cumprir as exigências de aplicabilidade Lei 10.639/2003 no sistema de ensino brasileiro, uma atividade metodológica, no qual pode ser utilizada na interdisciplinaridade das áreas em estudo, é a Contação de História, uma prática pedagógica eficaz para a construção de conhecimentos, valores e da identidade do aluno.

E neste sentido:

A contação de história é uma atividade interdisciplinar, pois envolve habilidades e conceitos de diversas áreas do conhecimento, especialmente das artes, sendo possível explorar os saberes geográficos, permitindo o ensino de história e cultura afro-brasileira, valorizando características pessoais, tipos de cabelo, cor da pele, lendas, e formas de pensar o mundo do povo afrodescendente, conforme pede a Lei $\mathrm{n}^{\circ}$ 10.639/2003 (RAMOS; GOMES; SAMPAIO, 2017, p. 69).

Uma prática proposta para o Ensino Médio, desenvolvida no em sala de aula a partir da necessidade de se trabalhar a questão do negro africano e da cultura afrobrasileira nos conteúdos de Geografia, será com análises bibliográficas de autores negros pelo professor de acordo com aspectos geográficos contidos nos livros selecionados. Essas práticas pedagógicas auxiliam os professores e suprem àqueles que possuem dificuldade em trabalhar a temática.

Ao usar a Literatura Negra nas aulas de Geografia, é possível demonstrar o negro como protagonista da sua própria história na formação do Brasil e com a educação escolar enfatizando a verdadeira história africana sem estereótipos e paradigmas eurocêntricos, será formado crianças plenas de sua origem e capazes de refletirem sobre a sua história.

Discutir o ensino de História da África e cultura afro-brasileira nas escolas é lembrar que o exercício da cidadania não pode ser constituído como privilégio para poucos, é necessário promover políticas de igualdade, justiça e solidariedade. Se um lugar como a escola reflete os dilemas da sociedade e se consideramos ela capaz de formar cidadãos ativos e conscientes de sua prática, é indiscutível ampliar o debate, profissionalizar os educadores e estabelecer experiências modificadoras que promovam autoestima e bemestar. (QUEIROZ; JUNIOR, 2016, p. 227). 
É preciso ressaltar a importância de apresentar livros que mostrem a história e cultura africana e afro-brasileira, onde reproduzem a realidade e a cultura das pessoas negras de forma positiva, e hoje existe uma variedade de obras literárias e contos interessantes disponíveis para download gratuitos, com personagens negros e com a temática africana e afro-brasileira, com a ideia de criar conteúdo de Geografia dialogando com a Literatura Negra Infantil em sala de aula, descontruindo ideologias racistas da identidade negra.

\section{CONSIDERAÇÕES FINAIS}

Mesmo após a implementação da Lei 10639/2003 no sistema educacional, suas implicações ainda não são trabalhadas de forma efetiva nas escolas, há dificuldade em incluir a História e Cultura Africana e Afro-brasileira no planejamento escolar, pela falta de formação e preconceito em trabalhar a temática africana e afro-brasileira, com materiais didáticos superficiais e com aspectos negativos e racistas, por isso, através da Literatura, o professor poderá selecionar livros literários de gêneros textuais distintos que retratem em sua narrativa a história dos povos africanos e indígenas, observando se a história e as ilustrações desses grupos étnicos estão representados de forma positiva, uma vez que podem conter estereótipos racistas.

Para a aplicabilidade da Lei no Ensino de Geografia, é possível utilizar a Literatura infantil, como forma de inserir ações e atividades pedagógicas em salas de aula. Estudando a África a partir da Contação de Histórias, o aluno será capaz de desconstruir visões reduzidas e equivocadas do continente e obterá maior conhecimento acerca das contribuições africanas e indígenas para a sociedade brasileira.

Cabe ao professor de Geografia ser um elemento mediador para auxiliar na ampliação da visão de mundo e facilitar o entendimento das questões étnico-raciais com discussões de conhecimentos geográficos, porém é importante que este docente esteja preparado para discutir a temática étnico-racial em sala de aula e descontruir os estereótipos criados pela sociedade, com o uso da Literatura Negra Infantil e de outras linguagens pedagógicas na Geografia, promovendo atividades que valorizem a cultura africano e afro-brasileira, assim com a capacidade de despertar o interesse dos alunos em uma sociedade igualitária e livre do racismo.

A Literatura Negra Infantil pode auxiliar na maneira em que a Geografia é ensinada, revalorizando os conteúdos ministrados em sala de aula e, com este recurso 
metodológico possibilita a aproximação com a Geografia da África e Afro-brasileira, ensinando os alunos sobre um Continente formado com muitos grupos étnico, figuras históricas importantes e a contribuição do povo negro para a formação da sociedade brasileira.

\section{REFERÊNCIAS}

BRASIL. Lei $\mathbf{N}^{\mathbf{0}}$ 10.639, de 9 de janeiro de 2003. D.O.U. de 10/01/2003. Brasília, 2003.

BRASIL. Parecer CNE/CP 3/2004, aprovado em 10/3/2004. Diretrizes Curriculares para a Educação das Relações Étnico-Raciais e para o Ensino de História e Cultura Afro-Brasileira e Africana, Brasília, DF, junho, 2005.

BONATO, A. et al. Interdisciplinaridade no ambiente escolar. In: Seminário de Pesquisa em Educação da Região Sul - ANPED, 2012, Caxias do Sul.

KLUG, André Quandt; TESSMANN, Jéssica Moara da Cunha. A Interdisciplinaridade no Ensino de Geografia. In: Congresso Brasileiro de Geógrafos - AGB, 7. 2014.

MELO, Carlos Augusto de; GONÇALO, Sandra Regina Pereira. Uma proposta de intervenção para o ensino da literatura afro-brasileira nas aulas de Língua Portuguesa no Ensino Fundamental. Letras \& Letras, Uberlândia, v. 33, n. 1, p. 95-118, jan./jul., 2017.

MOREIRA, Márcio de Araújo. Análise do Impacto da Lei 10639/2003 no ENEM 1998 a 2013. 2015. 98f. Dissertação (Mestrado em Relações Etnicorraciais). Rio de Janeiro: Centro de Educação Tecnológica Celso Suckow da Fonseca.

OLIVEIRA, Ana Flávia Borges de. A Representação do Negro no Livro Didático de Geografia do $8^{\circ}$ Ano do Ensino Fundamental. 2019. 46 f. Trabalho de Conclusão de Curso - Instituto de Geografia, Universidade Federal de Uberlândia, Uberlândia, 2019.

QUEIROZ, Graziella Fernanda Santos; JÚNIOR, Manoel Caetano do Nascimento. Ensino de História e Cultura Africana e Afro-brasileira: experiência docente no ensino fundamental. In: Encontro Estadual de História, 2016, ANPUH-PB.

RAMOS, João Paulo Bernardo; GOMES, Fernanda; SAMPAIO, Adriany de Ávila Melo. Contação de histórias na Geografia: contribuições para o ensino da história e cultura afro-brasileira. Revista Ed. Popular, Uberlândia, v. 16, n. 1, p. 63-71. 2017.

RIBEIRO, Djamila. Pequeno Manual Antirracista. São Paulo: Cia. das Letras, 2019.

RODRIGUES, Poliana Rezende Soares; AQUINO, Mirian de Albuquerque. A (in)visibilidade da Pessoa Negra na Literatura Infantil: impossibilidades de afirmação afrodescendente na escola. Cadernos Imbondeiro, João Pessoa, v.1, n.1, p. 1-8, 2010. 